Abstract PS8:171 Table 1 Disfuncion endotelial

\begin{tabular}{|c|c|c|c|}
\hline & No damage & Damage & \\
\hline Statin & $10,127 \%(8)$ & $22,5 \%(9)$ & $\mathrm{p}=0,122$ \\
\hline Antiplatelet agents & $21,52 \%(17)$ & $37,5 \%(15)$ & $p=0,101$ \\
\hline Smoker-Former smoker & $22,78 \%(8)$ & $25,0 \%(10)$ & $p=0,943$ \\
\hline Obesity & $20,78 \%(16)$ & $10,0 \%(4)$ & $\mathrm{p}=0,226$ \\
\hline Dyslipemia & $13,92 \%(11)$ & $32,5 \%(13)$ & $p=0,032$ \\
\hline Hypertension & $13,92 \%(11)$ & $47,5 \%(19)$ & $p<0,001$ \\
\hline Age at diagnosis & $30,94 \pm 9,68$ & $37,92 \pm 15,79$ & $\mathrm{p}=0,003$ \\
\hline Evolution time & $12,96 \pm 9,88$ & $18,73 \pm 13,13$ & $p=0,008$ \\
\hline SLEDAI & $2,47 \pm 2,79$ & $2,38 \pm 2,57$ & $p=0,856$ \\
\hline Corticoids & $39,24 \%(31)$ & $35,0 \%(14)$ & $\mathrm{p}=0,802$ \\
\hline Antimalarial drugs & $89,873 \%(71)$ & $87,5 \%(35)$ & $\mathrm{p}=0,759$ \\
\hline Inmunosuppressive & $35,443 \%(28)$ & $30 \%(12)$ & $\mathrm{p}=0,698$ \\
\hline Corticoids treatment previously & $53,165 \%(42)$ & $45 \%(18)$ & $p=0,517$ \\
\hline Cholesterol & $182,0933,49$ & $195,7035,45$ & $\mathrm{p}=0,042$ \\
\hline HDL cholesterol & $65,10 \pm 18,18$ & $56,85 \pm 15,78$ & $p=0,016$ \\
\hline LDL cholesterol & $100,61 \pm 28,93$ & $118,17 \pm 30,13$ & $p=0,003$ \\
\hline Triglycerides & $82,18 \pm 43,28$ & $106,38 \pm 49,76$ & $p=0,007$ \\
\hline
\end{tabular}

\section{Poster session 9: Miscelleanea}

\section{PS9:172 CHARACTERISTICS OF LUPUS NEPHRITIS IN SAUDI LUPUS PATIENTS: A RETROSPECTIVE OBSERVATIONAL STUDY}

I Al-Homood, A Almasmaly, M Albirdisi. King Fahad Medical City, Medical Specialities Department, Rheumatology Section, Riyadh, Saudi Arabia

\subsection{6/lupus-2018-abstract.215}

Objective The aim of this study is to evaluate the prevalence, clinical, laboratory and histological types of lupus nephritis (LN) among Saudi patients.

Methods This is a retrospective study that done at King Fahad Medical City, Riyadh, Saudi Arabia, where clinical and laboratory data collected for a period from 2011-2016. All patients fulfilled the Systemic Lupus International Collaborating Clinics classification criteria (SLICC).

Results Out of 112 patients, 103 (92.0\%) females, 9 (8.0\%) males, mean age $34(33.87 \pm 10.42)$ years. The mean of initial proteinuria level was $0.72 \mathrm{gm}(0.72 \pm 1.34)$ and the mean serum creatinine $34.00(82.33 \pm 83.88)$. The most common clinical characteristics were skin rash $70 \%$ and photosensitivity $61 \%$.

With regards to comorbidities; Hypertension was found in 31 (27.7\%), Hyperlipidemia in $16(14.3 \%)$ and Diabetes mellitus in $12(10.7 \%)$ of SLE patients.
Laboratory investigations revealed $67.0 \%$ had a positive ANA, $60.7 \%$ positive Anti DsDNA, $27.7 \%$ positive aPL, 17.9\% positive Anticardiolipin igG, $18.8 \%$ positive Anticardiolipin IgM, and B2glycoprotein IgG was positive in $8.9 \%$ of patients.

$44(39.8 \%)$ out of 112 patients had a kidney biopsy and the histological types were as follow; Focal segmental glomerulosclerosis (FSGS) 2.2\%, class I 2.2\%, class II 6.8\%, class III 27.2\%, class IV 43.1\%, V 6.8\%, minimal change disease (MCD) 2.2\%, Thrombotic Microangiopathy (TMA) 2.2\%, non-specific 2.2\% Normal 2.2\%, poor biopsy $2.2 \%$.

Conclusion

- The most notable clinical manifestations were skin rash $70 \%$ followed by photosensitivity 61\% and arthralgia 39\%.

- Patients with Hypertension, hyperlipidemia and diabetes mellitus had a higher risk of developing $\mathrm{LN}$ at any stage by 10\%-28\%.

- The commonest class of lupus nephritis among our patients as proven by kidney biopsy is class IV $43.1 \%$ followed by class III 27.2\%.

\section{PS9:173 TWO DECADES OF NEUROLUPUS}

ASX Pires, M Cunha, M Formigo, S Freitas, G Alves, J Cotter. Hospital da Senhora da Oliveira, Guimarães, Portugal

10.1136/lupus-2018-abstract.216 